\title{
REALIDAD Y PERSPECTIVAS DE LOS CENTROS DE INVESTIGACIÓN UNIVERSITARIOS EN AMÉRICA LATINA ANTE EL COVID-19*
}

\author{
Lisandro José Alvarado-Peña** \\ https://orcid.org/0000-0001-5097-811X \\ Rosas Amadeo Amaya Sauceda*** \\ https://orcid.org/0000-0002-8638-6834 \\ Edgar Alfonso Sansores Guerrero**** \\ https://orcid.org/0000-0002-4952-2737 \\ Aurea Elizabeth Rafael Sánchez ${ }^{* * * * *}$ \\ https://orcid.org/0000-0002-1943-7857
}

RECIBIDO: Marzo 2021 / ACEPTADO: Abril 2021 / PUBLICADO: Mayo 2021

\begin{abstract}
Como citar: Alvarado-Peña, Lisandro; Amaya Sauceda, Rosas; Sansores Guerrero, Edgar; Rafael Sánchez, Aurea. (2021). Realidad y perspectivas de los Centros de Investigación Universitarios en América Latina ante el Covid-19. Telos: revista de Estudios Interdisciplinarios en Ciencias Sociales, 23 (2), Venezuela. (Pp.435-449).

DOI: www.doi.org/10.36390/telos232.14
\end{abstract}

\section{RESUMEN}

La investigación en cualquier ámbito es un pilar de desarrollo y crecimiento para una nación. Sin embargo, en los países que conforman América Latina nunca se le ha dado la verdadera importancia que tiene, tanto gobiernos como empresas es poca la inversión que destinan a laboratorios y centros de investigación; quedando rezagada para quienes por vocación propia decide llevar a cabo nuevas investigaciones. Aunado a esto, ahora se le suma el impacto

\footnotetext{
* Este artículo es un producto de una investigación más amplia, la cual está adscrito a la sublínea de investigación: Gestión y Gerencia en Centros de Investigación en América Latina y el Caribe adscrita al Instituto de investigaciones de la Red REOALCEI, México.

** Doctor en Ciencias Sociales, mención: Gerencia. Diploma de Estudios Avanzados(DEA) dentro del Doctorado en Administración de Empresas en la Universidad Politécnica de Madrid (UPM)- España. Posdoctorado en Metodología de la Investigación, Socioformación y Desarrollo Humano en el Centro Universitario CIFE, México (en curso). Profesor e investigador de la Universidad del Zulia. Director ejecutivo de la Red Académica Internacional "Estudios Organizacionales en América Latina, el Caribe e Iberoamérica" (REOALCEI). Correo electrónico: lisandroinvestigacion@gmail.com; lisandro.investigacion.reoalcei@gmail.com

${ }^{* * *}$ Doctor en Ciencias de la Educación. Licenciado en Educación Secundaria con Especialidad en: Matemática, Física y Computación. Licenciado en Matemáticas. Licenciado en Psicología. Profesor a tiempo completo de la Facultad de Educación y Ciencias de la Comunicación de la Universidad Nacional de Trujillo (UNT)-Perú. Miembro investigador de REOALCEI, México. Correo electrónico: ramaya@unitru.edu.pe; amayasauceda@hotmail.com

**** Doctor en Estudios Organizacionales. Profesor Investigador de la Universidad de Quintana Roo, México. Dr. en Estudios Organizacionales. Miembro del Sistema Nacional de Investigadores, Nivel I, del Consejo Nacional de Ciencia y Tecnología (México). Miembro investigador (REOALCEI, México. Correo electrónico: edsan@uqroo.edu.mx

****** Doctorado en Administración, Magister en Tecnología Educativa, Diploma de Posdoctorado en Educación, Comunicación y Cultura, Diploma de Estudios en Alta Investigación Posdoctoral en Educación, Ciencias Sociales e Interculturalidad, Diplomado en Alta Gerencia Universitaria, Licenciatura en Educación Secundaria, especialidad matemática, Docente e Investigadora de la Universidad Nacional de Trujillo, Perú. Miembro de la Red Kipus Perú, red de docentes de América Latina, PUCP. Correo electrónico: elizabethrafaelsan@gmail.com; erafael@unitru.edu.pe
} 
Realidad y perspectivas de los Centros de Investigación Universitarios en América Latina ante el Covid-19

económico que ha generado la presencia del virus Covid-19; y las transformaciones que se han tenido que realizar en las distintas actividades humanas, donde la educación superior y sus actividades de extensión no quedaron exentas de esta nueva normalidad, planteando nuevos retos implícitos en el cambio de plataforma presencial a virtual para seguir dando respuestas a la sociedad ante este contexto de pandemia. Por lo cual, el objetivo fundamental del presente estudio es describir la realidad y perspectivas de los Centros de Investigación Universitarios en América Latina ante el Covid-19, a través de una revisión sobre la bibliografía existente sobre el tema, fundamentándose en autores tales como: Paredes-Chacín; et al (2020), Urbaneja (2020), UNESCO (2020), el Instituto Internacional para la Educación Superior en América Latina y El Caribe (2020), entre otros; bajo una metodología interpretativa, transversal entre los años 2020 y 2021. Obteniendo entre los hallazgos más relevantes que a pesar de la poca importancia y baja asignación presupuestaria que a nivel gubernamental se le otorga a la investigación dentro del sector universitario, estas instituciones han sabido salir adelante, sobretodo en estos momentos de pandemia, incorporando los medios digitales a sus actividades y aprovechando las oportunidades aperturadas a nivel internacional para el mundo de la ciencia y seguir produciendo conocimiento direccionado a lograr el desarrollo socioproductivo de los países.

Palabras clave: Investigación, Centros de Investigación, Educación universitaria, nueva normalidad, Covid-19.

\title{
Reality and perspectives of the University Research Centers in Latin America in the face of Covid-19
}

\begin{abstract}
Research in any field is a pillar of development and growth for a nation. However, in the countries that make up Latin America, it has never been given the true importance that it has. Both governments and companies have little investment in laboratories and research centers; lagging behind for those who by their own vocation decide to carry out new investigations. In addition to this, now we add the economic impact generated by the presence of the Covid-19 virus; and the transformations that have had to be carried out in the different human activities, where higher education and its extension activities were not exempt from this new normality, posing new challenges implicit in the change from face-to-face to virtual platform to continue giving answers to the society in this context of a pandemic. Therefore, the fundamental objective of this study is to describe the reality and perspectives of the University Research Centers in Latin America in the face of Covid-19, through a review of the existing bibliography on the subject, based on authors such as: Paredes-Chacín; et al (2020), Urbaneja (2020), UNESCO (2020), the International Institute for Higher Education in Latin America and the Caribbean (2020), among others; under an interpretive methodology, transversal between the years 2020 and 2021. Obtaining among the most relevant findings that despite the little importance and low budget allocation that at the government level is given to research within the university sector, these institutions have managed to forward, especially in these times of pandemic, incorporating digital media into its activities and taking advantage of the
\end{abstract}


opportunities opened at the international level for the world of science and continuing to produce knowledge aimed at achieving the socio-productive development of the countries.

Keyword: Research, Research Centers, University Education, New Normal, Covid-19.

\section{Introducción}

Las universidades desde sus comienzos siempre han constituido uno de los centros de capacitación, formación y disertación en diversas áreas más relevantes para los países y su crecimiento, dado que son instituciones cuya misión es formar, resaltar y/o construir valores éticos, criterios propios y fijación de paradigmas sobre las distintas áreas del pensamiento humano, su historia, evolución y desempeño cotidiano y laboral actual, con lo cual, establece las bases de su formación profesional.

Asimismo, las Universidades desde sus comienzos, siempre han sido un pilar fundamental en la formación tanto cultural como profesional de la sociedad durante distintas generaciones, siendo espacios de debates políticos, ambientales, sociales, económicos, entre otros, que permiten la construcción de criterios propios del estudiante en formación en base a los fundamentos teóricos aprendidos y las experiencias compartidas por sus profesores y compañeros.

Donde, la investigación resulta ser una actividad implícita dentro de la capacitación profesional del estudiante universitario, por esto, el desarrollo de las habilidades investigativas termina siendo una exigencia en el ámbito universitario, precisando que los estudiantes asuman la relevancia científica de la investigación a fin de lograr la calidad investigativa en su desarrollo profesional y académico (Fernández Espinoza y Villavicencio Aguilar, 2017); (Rojas Salazar; et al, 2019) y (Moreno Bayardo, 2005).

Ahora bien, de esos debates y de las situaciones que dentro de la contextualidad se van presentando a nivel de cualquier organización sea de naturaleza pública o privada, se derivan temas interesantes de investigación, análisis y reflexión donde los centros e institutos de investigaciones universitarios son el espacio propicio para desarrollar diferentes estudios que favorecen la generación de soluciones y alternativas óptimas para la toma acertada de decisiones asertiva dentro del ámbito que se esté estudiando y que sirvan para mejorar los niveles de desarrollo y crecimiento de la sociedad.

Por lo cual, los centros e institutos de investigación a nivel universitario constituyen espacios para desarrollar las actividades propias derivadas de la investigación, tal como expresan Quintero, Maza y Batista (2010), son lugares específicos dentro de las universidades destinados para la investigación, de los cuales se espera surjan planteamientos y alternativas de solución a diferentes problemáticas relacionadas con la contextualidad, así como innovaciones que permitan mejorar los niveles de competitividad a nivel internacional en diferentes campos organizativos con eficiencia y calidad, a fin de alcanzar mayores niveles de bienestar social y desarrollo sostenible.

Ahora bien, la situación que originó el COVID-19, hace ya más de un año, fue sorpresiva para muchos países, en especial, para los de América Latina, que no estaban preparados para asumir esta contextualidad y menos en una época marcada por una fuerte crisis producto de la baja en los indicadores económicos y sociales en porcentajes mayores al $5 \%$, según los datos presentados por la CEPAL, citado por Urbaneja (2020). 
Realidad y perspectivas de los Centros de Investigación Universitarios en América Latina ante el Covid-19

Este decrecimiento económico antes señalado, ha afectado durante las últimas décadas a muchos países, se ha observado una gran fuga de capitales intelectuales en busca de mejores condiciones de vida, personas bien formadas y capacitadas para aportar al desarrollo del país, emigran hacia otros, traduciéndose en bajo nivel de competitividad, productividad, recursos fiscales eficiencia y eficacia en esos países que registran altos índices de emigración.

Aunado a esto, dentro de las mismas universidades no existen mecanismos confiables que permitan realizar una evaluación objetiva para determinar las capacidades tanto de su personal académico como de los mismos medios que utilizan para en el proceso de enseñanza y de sus sistemas científicos, agudizándose esta situación aún más a raíz del Covid-19, que ha puesto en marcha un sistema de educación virtual o a distancia, para el cual no se estaba preparado, teniendo que improvisar y adaptar rápidamente sus estructuras para dar respuestas a sus estudiantes.

En este sentido, la comunidad del conocimiento se encuentra asumiendo un gran reto producto de la imprevista situación pandémica que se ha presentado mundialmente, por lo cual, se hace necesario el apoyo y concientización de toda la sociedad involucrada con el sistema universitario y de investigación, no solo a nivel regional, sino nacional e internacional, que permita a través de las herramientas de telecomunicación socializar información científica, tal como han decidido diferentes editoriales, al liberar permisos de acceso para bibliografías 0 fuentes de carácter científico importantes para fundamentar y ampliar el proceso de generación científica de conocimientos.

No obstante, aunque la incorporación de las herramientas de telecomunicación, aunado a las decisiones de las editoriales y demás comunidades del saber han permitido dar respuesta y continuidad a los procesos de investigación, superando así los obstáculos de acceso a la información dada la situación de confinamiento y paralización de actividades en el ámbito académico. Aún existe un importante porcentaje poblacional que presenta limitaciones tanto de recursos tecnológicos como de capacidades motrices que continúan limitando la generación de conocimiento.

Al respecto, Urbaneja (2020), señaló que la crisis a nivel sanitario surgida a raíz del virus Covid-19, aunado a los problemas sociales y económicos que ya venían afectando a las Universidades de América Latina causarán un impacto mucho mayor en los productos de investigación y demás actividades de investigación que se solían desarrollar dentro del campus de las instituciones universitarias trabajando en función del bienestar para la sociedad.

En función a lo anterior, se resalta la necesidad de impulsar el intercambio de información entre centros e institutos de investigación regionales, nacionales e internacionales, para complementar los procesos de generación de conocimiento, además permitiendo crear y fortalecer vínculos entre académicos, de donde pueden surgir grupos de investigación multidisciplinarios e internacionales que contribuyan con la resolución de diversos problemas acontecidos en diversas áreas del desarrollo humano y del medio ambiente.

Conforme a los planteamientos antes mencionados, la investigación que se presenta busca describir la realidad y perspectivas de los Centros de Investigación Universitarios en América Latina ante el Covid-19, buscando con los hallazgos encontrados dar evidencia de cómo se han ido consolidando nuevas tendencias para hacer investigación, incorporando a ella, herramientas tecnológicas, iniciando con una breve descripción de la cómo ha 
evolucionado la investigación universitaria en América Latina para luego desarrollar las características de los mencionados centros durante el Covid-19, mostrando cómo se han adaptado a la nueva normalidad en dichos países, finalizando con las perspectivas de cómo las universidades deben trabajar en conjunto sociedad, gobierno, empresas y universidades a fin de articular esta nueva normalidad para la investigación, haciéndola más multidisciplinaria.

Asimismo, bajo una metodología interpretativa, de carácter transversal, considerando los hechos ocurridos entre el año 2020 y principios del 2021, expresados por autores tales como Paredes-Chacín; et al (2020), Parra Contreras (2020), Urbaneja (2020) y Ordorika (2020), todos publicados en revistas arbitradas de alto impacto; así como documentos de la UNESCO y del Instituto Internacional para la Educación Superior en América Latina y El Caribe (2020), que muestran la realidad y perspectivas de los Centros de Investigación Universitarios ante el virus Covid-19, resaltando en ellos que las diferentes experiencias en el mundo investigativo generadas por la pandemia producto del virus antes mencionado, representa una gran oportunidad de cambio en la práctica investigativa universitaria, la cual, será propicia analizar en futuras investigaciones, tomando en cuenta los resultados que hayan generado para la sociedad.

\section{La investigación universitaria en Latinoamérica}

Desde el inicio de la tecnología han sido claros los beneficios producidos en el desarrollo del ser humano, razón por la cual, los países de América Latina han ido invirtiendo cuantiosas sumas de dinero para incorporar la mayor cantidad de herramientas tecnológicas a sus actividades rutinarias y también en el ámbito empresarial, organizacional e industrial, a fin de optimizar el desempeño de sus funciones, mejorar calidad de servicio y ganar tiempo y rapidez en sus procesos de producción y prestación de servicio (Banco Interamericano de Desarrollo, 2010).

No obstante, al relacionar lo anterior con las inversiones realizadas en las instituciones de educación superior para asumir nuevas tecnologías en sus procesos de formación y de prestación de servicio, se observa que el escenario es contrastante con la realidad del mundo empresarial. La situación financiera de las diferentes universidades, especialmente a nivel público, siempre ha sido muy limitada, dependiendo de asignaciones del gobierno central, que en la mayoría de países que conforman América Latina, más bien han recortado las partidas presupuestarias destinadas a la investigación y por lo tanto a las inversiones destinadas a la expansión de tecnologías y equipos (Martínez Garcés \& Barreto Fereira, 2018).

Al respecto, señala García Arocha (2016), la situación a nivel presupuestario que afrontan actualmente las universidades públicas ha desmotivado y prácticamente paralizado las distintas actividades relacionadas con investigación, las cuales se llevan a cabo en centros e institutos del campo universitario destinados para tales fines. A su vez, la profesora Aular de Durán (2016), citada por Martínez Garcés (2018), agrega, que las inversiones realizadas en ciencia y tecnología dentro de las universidades públicas de Latinoamérica, han sido mínimas, los diferentes gobiernos hablan dentro de sus planes de gobierno la importancia de hacer ciencia y de los avances tecnológicos e innovación, sin embargo, es poco el apoyo financiero destinado para ello. 
Realidad y perspectivas de los Centros de Investigación Universitarios en América Latina ante el Covid-19

Así lo confirma Dallanegra Pedraza (2004), durante las últimas décadas los esfuerzos de sector científico en el campus universitario, siempre han tratado de estar al día en materia de investigación y desarrollo, bajo el patrocinio básico de los gobiernos nacionales de América Latina, sin embargo, han visto como su asignación presupuestaria ha estado mermada y en muchos países sometidos bajo amenazas de privatización emanadas por los organismos gubernamentales representantes del sector universitario con el supuesto objetivo de lograr mayor eficiencia.

Continúa el autor antes señalado, caracterizando al entorno universitario por un franco deterioro en sus instalaciones, los equipos y sistemas con los que operan son obsoletos, existe falta de mantenimiento en muchos de sus espacios, por mantenimiento inadecuado, entre otras características que demuestran como los diferentes ajustes y reducciones presupuestarias que le han aplicado a las universidades, las ha llevado a decidir, simplemente por preferir pagar nominas a sus docentes y empleados a fin de brindarle respuesta educativa a sus estudiantes, descuidando otras actividades como las de investigación, compra de equipos e insumos, entre otras que igualmente terminan afectando el desempeño profesional de los miembros de la comunidad académica.

Lo anterior, se evidencia cuando se analizan los productos de investigación generados por estas casas de educación superior, pues la mayoría de los resultados publicados por sus revistas arbitradas, en congresos, foros y demás medios de difusión del conocimiento, son productos de investigadores internacionales o de académicos que por sus medios propios han logrado desarrollar ciertas investigaciones, financiando ellos mismos ese proceso (Pereira; et al, 2014).

En la actualidad, las Universidades principalmente de carácter público, sólo pueden proporcionarle a sus investigadores un espacio físico para desarrollar sus estudios; los cuales muchas veces ni siquiera cuenta con los equipos, herramientas e insumos necesarios para realizar el procesos de investigación, mucho menos existe la posibilidad de optar por algún tipo de financiamiento desde estas instituciones, obligando en gran cantidad de casos a que los investigadores abandonen o no puedan culminar con sus estudios.

Las Universidades públicas han dejado de asumir en sus presupuestos, el desarrollo de proyectos de investigación a nivel nacional. Por el contrario, son recibidos con honores aquellos quienes han decidido producto de la recesión económica y crisis política-social que se vive en sus países, irse a realizar estudios en Universidades de países más desarrollados, donde efectivamente desarrollan una excelente capacitación y desarrollan grandes experiencias y conocimientos pero que son poco aplicables a la contextualidad de los países de América Latina, (Arechavala Vargas, 2011), dejando estos países sin pensadores científicos que aporten alternativas viables para mejorar sus niveles de crecimiento y desarrollo nacional.

Por otra parte, pensar que los docentes 0 investigadores de Latinoamérica puedan escribir un libro es un caso aún más complejo, dado que las editoriales pensando en su beneficio particular, han planteado que al no ser muy comercial este tipo de bibliografía, los autores deben asumir los gastos involucrados en la edición del texto, lo cual hace casi imposible su publicación.

A modo de reflexión, según lo planteado anteriormente, se ha podido visualizar como en las universidades de Latinoamérica, las actividades de docencia parecen estar totalmente 
desvinculadas del proceso de investigación científica, durante los últimos años, los docentes se han encargado particularmente de ejercer su función estricta de formación académica, pensando en preparar profesionales para el mundo empresarial, es decir, formar empleados. No obstante, la formación de pensadores de futuro, emprendedores, científicos, innovadores que se forman del proceso investigativo universitario con visión de cambio para la sociedad, ha quedado para un selecto grupo, docentes de la vieja escuela que aún defienden el paradigma investigativo para el desarrollo y siguen apostando por él más por vocación que por los incentivos que obtienen.

\section{La nueva realidad de la investigación en las instituciones universitarias como respuesta a la situación de pandemia ante el Covid-19}

En los actuales momentos resulta evidente como la realidad del contexto universitario ha cambiado completamente y para alcanzar la transdisciplinariedad en las instituciones universitarias es necesario implementar nuevas estrategias de gestión que resulten más efectivas, ante una nueva realidad cambiante, pues los sistemas tradicionales aunque siguen siendo importantes, ya no son tan eficientes para el sistema educativo y la generación del conocimiento.

Los cambios tecnológicos, económicos y culturales, representan una fuente de nuevos ideales, paradigmas, formas de actuar, costumbres y con ello se motiva el estudio, experimentación, investigación, sobre la evolución e impactos generados por los distintos cambios y transformaciones ocurridas a lo largo del tiempo. Aunado a esto, la pandemia mundial existente a raíz del Covid-19, ha causado uno de los cambios más importantes en la sociedad, evidenciando como ésta última no está capacitada para ejercer control y adaptarse rápidamente a los nuevos escenarios cada vez más complejos surgidos por las variables diversas que se presentan en el tiempo (Parra Contreras, 2020), especialmente a nivel educativo, donde justamente la tecnología es la mayor protagonista para permitir la continuidad del proceso de enseñanza-aprendizaje de la sociedad, que producto del confinamiento vieron paralizado su proceso (Yong Castillo; et al, 2017).

A su vez, este cambio de la educación bajo esquemas presenciales hacia la educación virtual o a distancia o bajo la plataforma virtual, genera nuevas oportunidades, no solo para los que desean continuar su proceso de formación académica, sino también este sistema constituye una alternativa para personas con deficiencias para poder movilizarse 0 para aquellas que producto de sus compromisos laborales no pueden asistir de forma presencial a la institución educativa, generando así mayores oportunidades de desarrollo profesional para las sociedades a nivel mundial y con ello personas capacitadas para emprender, innovar y trabajar en pro del crecimiento y bienestar de un país (Juca Maldonado, 2016); (Chaves Torres, 2017).

La pandemia que se producido producto del COVID-19, ha obligado a las Universidades a reflexionar sobre el desempeño de sus actividades medulares desde una visión completamente nueva, puesto que a lo largo de este proceso vivido se han descubierto nuevas oportunidades, herramientas y metodologías que permiten realizar mejoras sustanciales en el aprendizaje, adaptado a las exigencias del mundo globalizado y ganando la motivación del estudiantado a fin de crecer en el mundo de la investigación generando 
Realidad y perspectivas de los Centros de Investigación Universitarios en América Latina ante el Covid-19

productos de calidad a la sociedad que deben ser socializados en los medios pertinentes para ello y alcanzar así mejores niveles de desarrollo social.

La paralización de la investigación es una de las consecuencias dentro del entorno pandémico producido por el Covid-19, así lo señala el Banco Interamericano de Desarrollo (BID, 2020), producto de las medidas de bio-seguridad establecidas a fin de evitar contagios, donde el distanciamiento social es una de ella, a consecuencia de esto, resultó afectada la continuidad de las actividades académicas especialmente aquellas que tienen que ver con la investigación, los laboratorios, que requieren la presencia de sus investigadores para desarrollar los procesos necesarios para generar ciencia. Siendo esto el mayor reto asumido por las Universidades, al tener que adaptarse a una estructura virtual que sea sostenible en el tiempo.

Por otra parte, según los estudios realizados por Paredes-Chacín; et al, (2020), se puede afirmar que las distintas universidades de América Latina, a pesar de sus limitaciones, se han podido adaptar a la nueva normalidad se la educación a distancia, como respuesta a la crítica situación que ha desencadenado la presencia del Virus Covid-19, que obligó a paralizar sus actividades. No obstante, no todas han podido lograr mayores avances en este proceso, son muchos los obstáculos a nivel financiero, de conectividad, de adaptación y capacitación de los miembros que forman parte de estas instituciones, aunado a la rapidez y la improvisación con que ha sido aplicado, como para poder empezar a ver impactos positivos dentro de la sociedad y sectores socio-productivos.

Al respecto, el Instituto para la Educación Superior en América Latina y el Caribe, ha presentado resultados sobre una investigación realizada en los distintos hogares de América Latina y el Caribe, en materia de conectividad y acceso en los hogares a dispositivos inteligentes o computador que permita desarrollar en los alumnos y profesores el proceso educativo de forma virtual, encontrando que solo el $45 \%$ de la población logra tener acceso al internet y a equipos de telecomunicación, es decir, uno de cada dos hogares puede llevar a cabo fácilmente un proceso educativo a distancia (IESALC, 2020).

Por lo cual, la universidad, como institución dedicada al saber, matriz del conocimiento científico, debe aprovechar esta eventualidad y adaptar metodologías mixtas, en sus programas de educación, abriendo oportunidades para tanto los participantes regulares como para los que por alguna razón no pueden asistir de forma presencial al aula de clases, pero desea y requiere formarse profesionalmente; además las universidades deben mostrarse más a través de sus investigadores ofreciendo respuestas innovadoras a todos los problemas que el Covid-19 ha traído, con esto buscar el apoyo de otras organizaciones a nivel privado, que impulsen las investigaciones, revelación de resultados sobre los impactos pre y post-Covid, intercambio de experiencias, en fin crear vínculos, alianzas, a nivel internacional que permitan el crecimiento, reconocimiento y acreditación de las mismas, a través de sus productos de investigación y preparación de sus estudiantes, docentes e investigadores.

\section{Centros de Investigación Universitarios en América Latina durante la pandemia del Covid-19}


Conforme lo planteado en el Registro Nacional de centros de investigación (2018), citado por Rojas Rivas y Rojas Rivas (2019), establece que la función que cumplen primordialmente los centros de investigación es justamente la investigación sea científica o tecnológica, sin embargo, éstos también desempeñan otro tipo de funciones, pero que están más vinculadas hacia la ciencia y la tecnología, entre las cuales se pueden mencionar la capacitación profesional al capital humano, la difusión y divulgación de hallazgos científicos, entre otras actividades que permitan mantener en actualización constante a todos sus miembros e interesados en general sobre los avances de la ciencia.

Sin embargo, la inestabilidad que en estos tiempos ha afectado el sistema de salud a nivel mundial originado luego de la pandemia por Covid-19, ha forzado a cambiar las formas tradicionales de trabajo y educación, adaptándose a los sistemas a distancia, lo que ha sido considerado como un aporte para la gestión educativa y poder a través de ello darle continuidad al desarrollo de la actividades de enseñanza a todo nivel, al igual que los procesos referidos a la investigación (Paredes-Chacín; et al, 2020).

Por otra parte, Ordorika (2020), en una encuesta que se llevó a cabo por la International Association of Universities (IAU, Marinoni et al., 2020), se muestran ciertas cifras que describen cómo la eventualidad de la pandemia ha afectado la educación universitaria y las actividades de investigación a nivel mundial. Evidenciando como el $80 \%$ de las universidades señala que las actividades antes mencionadas han resultado afectadas, siendo el mayor impacto, sobre los viáticos internacionales la cual ha sido cancelada en $83 \%$, seguidamente, los gastos por conferencias científicas en un $81 \%$ y finalmente, el $52 \%$ afirma que en 10 referido a proyectos de investigación estos no serán culminados por falta de recursos.

No obstante, a pesar de las circunstancias antes mencionadas, aún se pudo cuantificar en la investigación antes mencionada, que un $41 \%$ de las universidades, están desarrollando proyectos de investigación referidos al impacto del COVID-19, en diversos sectores socioeconómicos, a fin de demostrar cuales han sido los beneficios 0 aspectos negativos que originaron los diversos cambios ocurridos para asumir la nueva normalidad y contribuir con la formación de políticas públicas que favorezcan el desarrollo en los diferentes países.

Específicamente, la Organización de las Naciones Unidas para la Educación, la Ciencia y la Cultura (2020), señala que Enero del año 2020, se expusieron en PubMed10 artículos pioneros sobre estudios en materia de Covid-19, ahora después de cinco meses se han podido registrar mucho más de 24.000 artículos científicos, esto demuestra que el esfuerzo a nivel científico mundial ha sido relevante durante los meses de abril y junio del 2020; aproximadamente a razón de un $3 \%$ de crecimiento diario, permitiendo acumular rápidamente un cúmulo de conocimiento (p.45).

Gráfico 1: Cantidad de artículos científicos publicados por países durante Covid-19 
Realidad y perspectivas de los Centros de Investigación Universitarios en América Latina ante el Covid-19

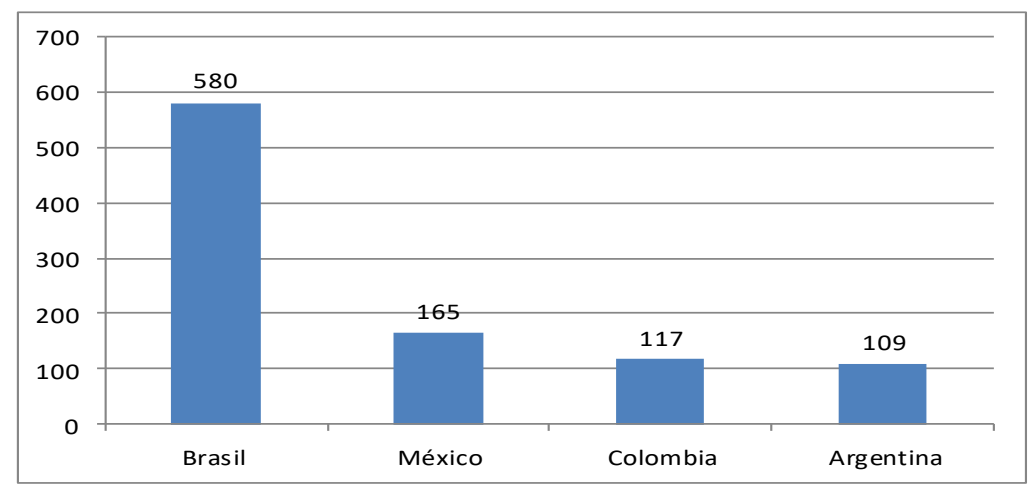

Fuente: Elaboración propia, en base a datos publicados por la Organización de las Naciones Unidas para la Educación, la Ciencia y la Cultura

Asimismo, la Organización de las Naciones Unidas para la Educación, la Ciencia y la Cultura (2020), indica que para ya para finalizar el mes de junio del años 2020, los países de Latinoamérica, a través de los investigadores de los centros universitarios ya habían logrado publicar artículos científicos en diversas revistas indizadas a nivel internacional, según se muestra en la figura 1, donde se resalta el papel trascendental que han tenido las universidades de dichos países para sumar los esfuerzos en materia de investigación.

Figura 1: Cantidad de universidades que han publicado artículos durante el 2020.

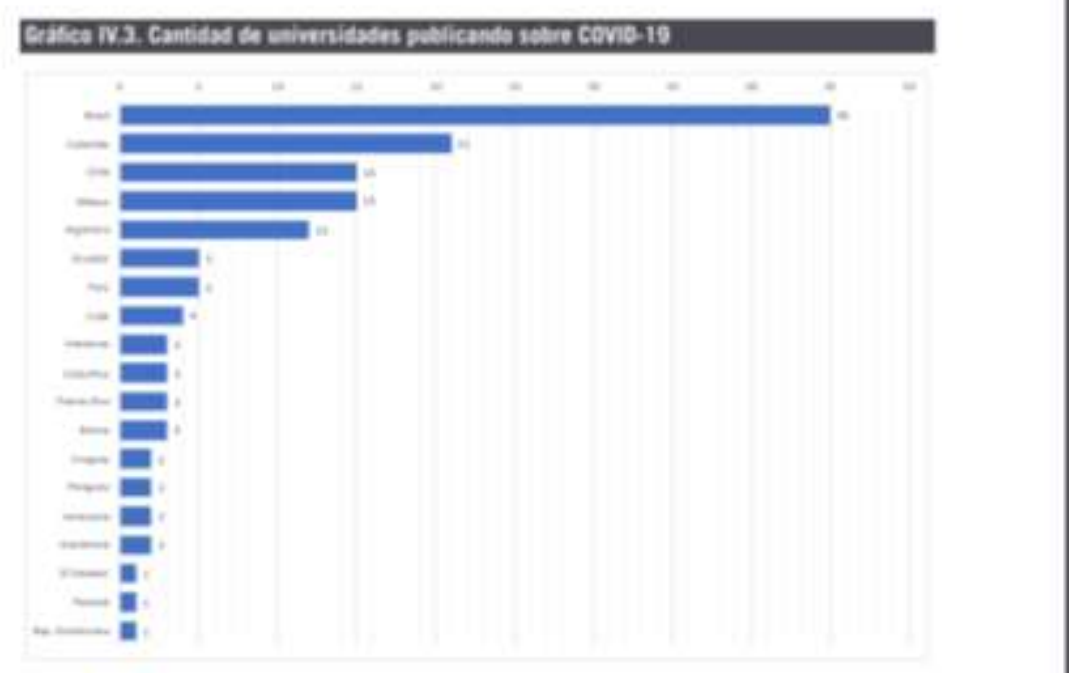

Fuente: Organización de las Naciones Unidas para la Educación, la Ciencia y la Cultura (2020), en base a datos de PubMed. Datos acumulados al 23 de junio de 2020. 
En general, se puede decir, que los centros de investigación universitarios, a pesar de haber cerrado sus puertas luego de la situación de alerta en materia de salud originada producto del Covid-19, muchos de ellos continuaron la producción de conocimiento aprovechando las ventajas de los medios de telecomunicación y el desbloqueo de muchas editoriales para acceder a publicaciones vía electrónica, y con ello seguir con sus propósitos, además de lograr ampliar los vínculos entre los diversos centros e institutos de investigación a nivel internacional y generar ciencia que trascienda las fronteras y sea beneficiosa para todos los países. Siendo esto un ejemplo a repetir por otras universidades a nivel mundial.

\section{Perspectivas de la investigación universitaria y sus Centros de investigación en América Latina}

La educación superior durante las últimas décadas, aunada quizás una de sus actividades primordiales para el desarrollo de la sociedad como lo es la investigación, han alcanzado avances significativos, contando para ello con el apoyo de organismos multilaterales quienes regulan las vertientes educativas Latinoamericanas (Paredes-Chacín; et al, 2020). Donde, uno de esos avances ha sido la incorporación de las tecnologías denominadas TIC dentro de los procesos de enseñanza-aprendizaje, direccionado a satisfacer las exigencias de las sociedades en materia de conocimientos e innovación.

Asimismo, señalan Paredes-Chacín; et al (2020), entre las primeras consecuencias originadas a corto plazo producto de la crisis sanitaria del Covid-19, está la disminución de la matricula estudiantil, seguida de la interrupción o paralización de las actividades investigativas universitarias y gestión del conocimiento, teniendo que asumir nuevas inversiones en materia de recursos tecnológicos, especialmente de telecomunicación, a fin de adaptar rápidamente sus sistemas de educación a la modalidad virtual.

Para los autores Aguilar y Bustelo (2010), es requerido que las instituciones universitarias asuman un nuevo modelo de gestión, más flexible, adaptado a la nueva normalidad, que además de incorporar los medios de telecomunicación a sus procesos de enseñanza, debe buscar la asociación entre organismos gubernamentales, sector empresarial y la misma comunidad con la finalidad de optimizar el uso y distribución de sus recursos, contar con apoyo privado para invertir en sus laboratorios y centros de investigación, así como en herramientas tecnológicas que faciliten los procesos educativos, de investigación y donde ésta interacción entre sectores, les permita conocer mejor las necesidades sociales y generar productos de real impacto para el beneficio de las comunidades que todo país espera de estas casas de estudio profesional.

Ahora bien, está búsqueda de alternativas integrales entre diversos actores debe ser permanente, no solo durante la pandemia del Covid-19, asimismo, debe estar enfocada en responder a los lineamientos establecidos dentro de la responsabilidad social y a su vez, relacionada con la contextualidad, a fin de que los procesos de enseñanza-aprendizaje, también estén direccionados en ese sentido, adaptando sus conocimientos a esa realidad existente y generando soluciones efectivas y acordes con los esquemas cambiantes de las distintas organizaciones que evolucionan cada día y que la gestión educativa debe enfocar para evolucionar y adaptarse al mismo ritmo, formando profesionales con alta competitividad para el mundo dinámico actual (Miranda Torres, 2015); (Garzón Castrillón, 2015). 
Realidad y perspectivas de los Centros de Investigación Universitarios en América Latina ante el Covid-19

En este sentido, las instituciones de educación superior, deben ser quienes desde sus centros de investigación, desarrollen teorías, paradigmas, políticas de actuación y desarrollo, innovaciones, para los distintos sectores que se encargan de la producción y prestación de servicios, al igual que para organismos dependientes del gobierno, que los lleven a mejorar su eficiencia productiva y de gestión, garantizando el uso óptimo de recursos y no dejarse dominar como hasta ahora ha sido, que las competencias que se acuerdan desarrollar en las universidades surgen de las prácticas organizativas y no de las universidades que son la fuente que debería generar el conocimiento y la praxis del mundo profesional.

A lo anterior, agrega Dallanegra Pedraza (2004), las universidades deben estar vinculadas al sector científico para así construir el conocimiento en relación a las necesidades y exigencias propias de las comunidades, pues la razón de ser de toda universidad radica en su función de creatividad, desarrollo e innovación, además de la sobreentendida función de educar, es quien debe establecer el camino a seguir de la sociedad. En caso contrario, solo sería una institución transmisora de conocimientos generados por otros, trayendo como consecuencia más estancamiento para Latinoamérica.

Por su parte, la UNESCO (2020), señala que es importante garantizar la unificación entre gobierno, entes humanitarios, sectores productivos y universidades para dar respuestas oportunas, gestionando los riesgos, así como la ciencia y tecnología, para planificar estrategias que conlleven al crecimiento y desarrollo de la economía en la búsqueda de mejorar los niveles de la calidad de vida y bienestar de la población, antes y después del Virus Covid-19, sobre todo en América Latina normalmente caracterizados por enfrentar situaciones de crisis socioeconómicas.

A modo de reflexión, si el objetivo que realmente se busca es generar transformaciones para la sociedad de América Latina, direccionados hacia su bienestar y desarrollo como nación, lo que se requiere es modificar sus estructuras de liderazgo, gobierno y gestión enfocadas no solo en cuanto a la protección del ambiente, junto a los recursos naturales renovables y no renovables, sino partir principalmente desde los programas de educación, las formas para construir conocimiento, formar seres con mentalidad emprendedora, de investigación, de innovación, capaz de desarrollar nuevas herramientas, teorías, enfoques, adaptados a la contextualidad que permitan evolucionar en el tiempo.

\section{Reflexiones Finales}

Conforme a la investigación realizada y los hallazgos encontrados se puede afirmar que las universidades de América Latina durante su proceso de enseñanza-aprendizaje no está formando ni permitiendo desarrollar a los futuros pensadores, investigadores y hacedores de ciencia, solo se ha dedicado a la mera capacitación de profesionales, con mentalidad de empleados y no de emprendimiento ni de innovación, que permitan desarrollar novedosas herramientas o soluciones a las diversas deficiencias del mundo organizacional.

Esto derivado del desestimulo que reciben las mencionadas universidades en cuanto al sus actividades de extensión, investigación y desarrollo producto de asignar cada vez menos presupuestos a estas instituciones y desestimar la importancia en la dotación de tecnologías vanguardistas, lo cual, se traduce en retroceso y pérdida de competitividad para el sistema educativo comparado con otros países antes, durante y después del Covid-19. 
Por lo cual, se debe fomentar el apoyo de los diversos sectores hacia las Universidades, sobre todo en inversiones de tecnología, instrumentos e insumos para sus laboratorios, entre otros aspectos importantes para reactivar el mundo de la investigación y desarrollo dentro de las instituciones universitarias, bajo los lineamientos de ciencia y tecnología, que lleven a formular estrategias, recomendaciones, teorías e instrumentos que permitan prever oportunamente los riesgos a nivel empresarial, contribuyendo al desarrollo y calidad de vida, además de satisfacer las necesidades educativas universitarias en América Latina ante el COVID-19, pero que a la vez garanticen su sostenibilidad en el tiempo.

Donde, la capacidad de adaptación e iniciativas asumidas por las diferentes instituciones universitarias, a fin de dar respuesta a sus miembros para poder continuar sus actividades de formación profesional y de investigación, incorporando los medios digitales y de telecomunicación a sus estrategias de enseñanza a raíz de la situación de confinamiento social por el Covid-19, es considerado una transformación que ha trascendido fronteras, superando las expectativas de organismos multilaterales, quienes daban por hecho que estas instituciones no continuarían con sus actividades regulares. Esto se ha podido alcanzar gracias al esfuerzo conjunto entre docentes, investigadores, estudiantes y colaboradores que apostaron por el avance permitiendo logran la continuidad de sus procesos de formación e investigación a través de mecanismos virtuales.

En este sentido, las experiencias que han obtenido las universidades durante el proceso de adaptación y cambios surgidos repentinamente tras el Covid-19, deben sentar las bases para el surgimiento de espacios de reflexión e iniciativas de cooperación y alianzas entre empresas-gobierno y universidades tanto nacionales como internacionales, a fin de trabajar de forma coordinada y uniendo esfuerzos en la búsqueda del bienestar no solo del propio país, sin buscando ayudar a solventar las problemáticas internacionales, que el camino a donde apunta todo este proceso de globalización y vinculación entre países a través de la modalidad virtual para llevar a cabo actividades de educación.

Finalmente, se recomienda realizar futuras investigaciones que giren en torno a la evaluación de las políticas que han sido aplicadas por los diversos sectores empresariales, industriales y gubernamentales para impulsar la ciencia y tecnología dentro de las distintas instituciones, así como los avances, resultados alcanzados a raíz de la aplicación de estrategias para afrontar los impactos generados por el Covid-19 y cómo estas se proyectaron ante la sociedad del conocimiento en el ámbito nacional e internacional en tiempos de pandemia.

\section{Referencias Bibliográficas}

Aguilar, Luis y Bustelo, María. (2010). Gobernanza y evaluación: una relación potencialmente fructífera. Revista Gestión y Análisis de Políticas Públicas, (4), España (Pp: 2351). Extraído de: http://www.redalyc.org/pdf/2815/281521696002.pdf

Arechavala Vargas, Ricardo. (2011). Las universidades y el desarrollo de la investigación científica y tecnológica en México: Una agenda de investigación. Revista de la educación superior, 40 (158), México. (Pp: 41-57). Extraído de: http://www.scielo.org.mx/pdf/resu/v40n158/v40n158a3.pdf

Banco Interamericano de Desarrollo (BID, 2010). Ciencia, Tecnología e innovación en América Latina

el

Caribe.

Extraído

de: 
Realidad y perspectivas de los Centros de Investigación Universitarios en América Latina ante el Covid-19

https://publications.iadb.org/publications/spanish/document/Cienciatecnolog\%C3\%ada-e-innovaci\%C3\%b3n-en-Am\%C3\%a9rica-Latina-y-el-Caribe-Uncompendio-estad\%C3\%adstico-de-indicadores.pdf

Banco Interamericano de Desarrollo (BID, 2020). La educación superior en tiempos de Covid-19. Extraído de: https://publications.iadb.org/publications/spanish/document/La-educacion-superioren-tiempos-de-COVID-19-Aportes-de-la-Segunda-Reunion-del-Di\%C3\%A1logoVirtual-con-Rectores-de-Universidades-Lideres-de-America-Latina.pdf

Chaves Torres, Anivar. (2017). La educación a distancia como respuesta a las necesidades educativas del siglo XXI. Revista Academia \& Virtualidad, 10 (1), España. (Pp: 2341). DOI: http://dx.doi.org/10.18359/ravi.2241

Dallanegra Pedraza, Luis. (2004). La Universidad y la investigación científica en América Latina. IDICSO - Serie Documentos de Trabajo, (23), Argentina. (Pp:1-32). Extraído de: http://csoc.usal.edu.ar/archivos/csoc/docs/idicso-sdti023.pdf

García Arocha, Cecilia. (2016). Universidades pueden paralizarse por falta de presupuesto. Entrevista publicada por el Nuevo Herald. Caracas-Venezuela. Extraído de: https://www.elnuevoherald.com/noticias/mundo/america-latina/venezuelaes/article62426937.html

Garzón Castrillón, Manuel (2015). Modelo de capacidades dinámicas. Revista Dimensión Empresarial, 13 (1), Colombia. (Pp: 111-131). Extraído de: http://www.scielo.org.co/scielo.php?pid=S1692$85632015000100007 \&$ script=sci_abstract\&tlng $=e s$

Fernández Espinosa, Cira y Villavicencio Aguilar, Carmita (2017). Habilidades investigativas para trabajos de graduación. ACADEMO Revista De Investigación En Ciencias Sociales $Y$ Humanidades, 4(1), Paraguay. Extraído de: https://revistacientifica.uamericana.edu.py/index.php/academo/article/view/61

Instituto Internacional para la Educación Superior en América Latina y El Caribe - IESALC (2020). COVID-19 y educación superior: De los efectos inmediatos al día después. Análisis de impactos, respuestas políticas y recomendaciones. Extraído de: http://www.iesalc.unesco.org/wp-content/uploads/2020/05/COVID-19-ES-130520.pdf Juca Maldonado, Fernando. (2016). La educación a distancia, una necesidad para la formación de los profesionales. Revista Universidad y Sociedad, 8 (1), Cuba. (Pp: 106-111). Extraído de: http://scielo.sld.cu/pdf/rus/v8n1/rus15116.pdf

Martínez Garcés, Josnel (2018). Planeación para la inversión tecnológica en centros de investigación universitarios. Revista CICAG, 16 (1), Venezuela. (Pp: 143-159). Extraído de: http://ojs.urbe.edu/index.php/cicag/article/view/2941/3715

Martínez Garcés, Josnel \& Barreto Fereira, Javier (2018). Centros de investigación universitarios e inversión tecnológica: ¿en qué se invierte? Revista Innovare, 7 (2), Honduras. (Pp: 1-13). DOI: http://dx.doi.org/10.5377/innovare.v7i2.8078

Miranda Torres, Julián (2015). El modelo de las capacidades dinámicas en las organizaciones. Investigación Administrativa, (116), México (Pp: 81-93). Extraído de: http://www.redalyc.org/pdf/4560/456044959005.pdf 
Moreno Bayardo, María (2005). Potenciar la educación. un currículum transversal de formación para la investigación. Revista Iberoamericana sobre Calidad, Eficacia y Cambio en Educación, 3(1), España. (Pp: 520-540). Extraído de: https://www.redalyc.org/articulo.oa?id=55130152

Ordorika, Imanol (2020). Pandemia y educación superior. Revista de la educación superior. 49 (194). México. (Pp: 83-108). Extraído de: https://www.researchgate.net/publication/346938048_Pandemia_y_educacion_superi or

Parra Contreras, Reyber (2020). Una perspectiva del mundo que se nos avecina. Revista de la Universidad del Zulia. 3aépoca, 11 (29), Venezuela. (Pp: 3-5). Extraído de: https://www.produccioncientificaluz.org/index.php/rluz/article/view/31532/32613

Paredes-Chacín, Ana; Inciarte González, Alicia y Walles-Peñaloza, Daniela. (2020). Educación superior e investigación en Latinoamérica: Transición al uso de tecnologías digitales por Covid-19. Revista de Ciencias Sociales, XXVI (3), Venezuela. (Pp: 98-117). DOI: https://doi.org/10.31876/rcs.v26i3.33236

Pereira, Aracelys; Casanova, Mery; Pire, Reinaldo. (2014). Estudio comparativo de la producción científica de las universidades públicas y privadas venezolanas. $\begin{array}{lllll}\text { Compendium, } & 17 & (32), & \text { Venezuela. } & \text { (Pp: }\end{array}$ https://www.redalyc.org/pdf/880/88037910004.pdf

Quintero, Johana., Maza, Eliumat. y Batista, Judeira (2010). Gerencia de Investigación y desarrollo en centros de investigación de Universidades Públicas Colombianas. Revista Telos, 12 (3), Venezuela. (Pp: 275-286). Extraído de: https://www.redalyc.org/pdf/993/993171068002.pdf

Rojas Rivas, María y Rojas Rivas, Marling (2019). Centros de investigación universitarios, una mirada desde la Ecología del Desarrollo Humano, Educere, 23 (76), Venezuela. Extraído de: https://www.redalyc.org//atsRepo/356/35660459005/html/index.html

Rojas Salazar, A., Castro Llaja, L., Siccha Macassi, A. y Ortega Rojas, Y (2019). Desarrollo de habilidades investigativas en estudiantes de enfermería: Nuevos retos en el contexto formativo. Investigación Valdizana, 13(2), Perú. (Pp: 107-112). DOI: https://doi.org/10.33554/riv.13.2.236

UNESCO (2020). Crisis-sensitive educational planning. (Education Sector issue notes $n^{\circ} 2.4$ ). Extraído de: http://www.iesalc.unesco.org/en/wp-content/uploads/2020/04/COVID-19Education-Issue-Note-2.4-Planning.pdf

Urbaneja, Rosiris (2020) Investigación en Venezuela: ¿Volver a la normalidad o transformar la realidad? Extraído de: http://guayanaweb.ucab.edu.ve/noticias-reader-guayanaactual/items/investigacion-en-venezuela-volver-a-la-normalidad-o-transformar-larealidad-1798.html

Yong Castillo, Erika; Nagles García, Nofal; Mejía Corredor, Carolina y Chaparro Malaver, Carmen. (2017). Evolución de la educación superior a distancia: desafíos y oportunidades para su gestión. Revista Virtual Universidad Católica del Norte, 50, Colombia. (Pp: 80-105). Extraído de: https://www.redalyc.org/pdf/1942/194250865006.pdf 